\title{
Genetic Polymorphisms of CYP2C9: Comparison of Prevalence in the Lebanese Population with Other Populations'
}

\author{
Yolande B. Saab ${ }^{1}$, Taimour Langaee ${ }^{2}$ \\ ${ }^{1}$ School of Pharmacy, Lebanese American University, Byblos, Lebanon; ${ }^{2}$ Center for Pharmacogenomics, College of Pharmacy, Uni- \\ versity of Florida, Gainesville, USA. \\ Email: ysaab@lau.edu.lb
}

Received January $15^{\text {th }}, 2011$; revised February $28^{\text {th }}, 2011$; accepted March $10^{\text {th }}, 2011$.

\begin{abstract}
Background: There is little knowledge about genotyping of cytochrome P450s in the Middle East, and there has not been any report on the genotype of CYP2C9 allelic variants in Lebanese population. Aims and objectives: The purpose of the study was to determine and compare the frequencies of the cytochrome P450 CYP2C9 variants in the Lebanese population with the frequencies in other ethnic populations. Methods: CYP2C9 genotypes were determined in a total of 146 samples of unrelated, healthy Lebanese individuals residing in different areas in Lebanon. Following DNA extraction from buccal cells and polymerase chain reaction, genotyping was performed by Pyrosequencing method. CYP2C9 genotypes results were compared to other populations'; i.e., Middle Easterns, Europeans, Asians, and African Americans. Results and discussion: The frequencies of the CYP2C29*2, CYP2C9*3, and CYP2C9*4 alleles were $11.305 \%$, $11.645 \%$, and $1.025 \%$ respectively. No CYP2C9*5 allele variants were found among the Lebanese study sample. Volunteers could be divided into three CYP2C9 genotype groups: subjects $(76.71 \%)$ with no mutated alleles (CYP2C9*1*1; homozygous extensive metabolizers, EM), $21.23 \%$ with one mutated allele (CYP $2 C 9 * 1 * 2, * 1 * 3, * 1 * 4$, and $* 1 * 5$; heterozygous intermediate metabolizers IM), and $2.06 \%$ with two mutated alleles, homozygous variants as poor metabolizers, PM). The comparative analysis using genotype groups of different populations showed differences among Lebanese and other Caucasians. Conclusion: This is the first report from Lebanon on CYP2C9 variants; it highlights a higher frequency of CYP2C9 extensive metabolizers compared to other populations including Caucasians. The results serve as a database on CYP 2 C9 polymorphisms and baseline clinical data for dosing and avoiding adverse drug reactions of drugs metabolised by CYP2C9 in Lebanese patients.
\end{abstract}

Keywords: CYP2C9, Gene Polymorphisms, Lebanese, Middle East

\section{Introduction}

The cytochrome P-450 system (CYP) is responsible for the metabolism of several naturally occurring and synthetic compounds. The CYP2C9 isoenzyme is primarily responsible for the oxidative metabolism of several drugs, including warfarin, phenytoin, losartan, irbesartan, tolbutamide, glipizide, torsemide, and various nonsteroidal anti-inflammatory drugs [1]. Multiple single nucleotide polymorphisms within the gene for CYP2C9 have been identified, and at least 13 of these encode CYP2C9 alleles [2,3]. Three alleles, CYP2C9*1, *2 and *3, are present in most ethnic populations. The most common allele is designated $* 1$ and is considered the wild-type allele. The *2 allele results from a single base substitution (430
$\mathrm{C}>\mathrm{T})$ that is located in exon 3 . The $* 3(1075 \mathrm{~A}>\mathrm{C}), * 4$ $(1076 \mathrm{~T}>\mathrm{C})$, and $* 5(1080 \mathrm{C}>\mathrm{G})$ alleles result from base changes located in exon 7 . In addition, some null polymorphisms have been recently identified except for CYP2C9*34 in Japanese population [3]. The *2 and *3 alleles encode a protein with reduced enzymatic activity in vitro, and patients with these alleles have been designnated as "poor metabolizers" $[4,5]$, that may experience drug toxicity. Thus the dose of these drugs may need to be adjusted according to CYP2C9 genotype. The genotype distribution among individuals varies with ethnic background. In Caucasian populations, for example, approximately two thirds of individuals express the wildtype genotype, $* 1 / * 1$; one third express the $* 1 / * 2$ or $* 1 / * 3$ genotype; and fewer than $2.5 \%$ express the $* 2 / * 2$, 
$* 2 / * 3$, or $* 3 / * 3$ genotype [2]. The allele frequencies of CYP2C $9 * 2$ and CYP2C9*3 tend to be greater in Caucasians populations compared to African-American and Asian populations; the CYP2C $2 * 2$ was not found in East Asians including Chinese and Japanese [6].

To our knowledge, there is little knowledge about genotyping of cytochrome P450s in the Middle East, and there has not been any report on the genotype of CYP2C9 allelic variants in Lebanese population who are considered White Caucasians. Lebanon is a small country of $10500 \mathrm{~km}^{2}$ on the eastern shores of the Mediterranean Sea; it has made a historical crossroads between Asia, Africa, and Europe. Today, the population is approximately 4 million people, with a worldwide diaspora estimated at 16 million. Thus the purpose of the study was to determine the CYP2C $9 * 1, \mathrm{CYP} 2 \mathrm{C} 9 * 2, \mathrm{CYP} 2 \mathrm{C} 9 * 3$, $\mathrm{CYP} 2 \mathrm{C} 9 * 4$, and $\mathrm{CYP} 2 \mathrm{C} 9 * 5$, allele and genotype frequentcies in Lebanese and compare with other populations. The results will serve as baseline clinical data for dosing of drugs metabolised by CYP2C9 based on Lebanese patients' genotypes and avoiding the adverse drug reactions.

\section{Materials and Methods}

\subsection{Subjects}

A total of 146 healthy volunteers were recruited from the Lebanese population. All subjects signed a consent form. Included were non-obese subjects (body mass index $(\mathrm{BMI})<29.5 \mathrm{Kg} / \mathrm{m}^{2}$ ), with no history or clinical evidence of diabetes, cardiovascular problems, hypertension, renal insufficiency, and/or depression. All study subjects are of Lebanese origin, and were living in Lebanon at the time of study. The School of Pharmacy research com- mittee approved the project.

\subsection{CYP2C9*2*3*4*5 Gene Polymorphism Genotyping}

Each volunteer was asked to give a DNA sample from the cheek using a cheek swab. DNA was isolated from cheek swabs by a method previously described [7].

Genotype polymorphisms for the CYP2C $9 * 2, * 3, * 4$, and $* 5$ alleles was performed by means of PCR (MyCycler; BioRad laboratories, Hercules, Calif) followed by Pyrosequencing [8] by using PSQ HS 96A System (Biotage $\mathrm{AB}$ ), with use of automated PSQ HS 96A SNP software (Biotage $\mathrm{AB}$ ); a previously validated protocol [9]. In brief, the PCR reaction mixture used for target sequence amplification consisted of $13 \mu \mathrm{l}$ of HotStarTaq Master Mix (Qiagen), 10 pmol of each primer (Invitrogen) $(1 \mu \mathrm{lL})$, and $50-100 \mathrm{ng}(10 \mu \mathrm{l})$ of genomic DNA. Primer sequences are as detailed in Table 1 [10]. The PCR amplification was performed under the following conditions: initial denaturation at $95^{\circ} \mathrm{C}$ for 15 minutes, 45 cycles of denaturation at $95^{\circ} \mathrm{C}$ for 30 seconds, annealing at $55^{\circ} \mathrm{C}$ for 30 seconds, and extension at $72^{\circ} \mathrm{C}$ for $1 \mathrm{~min}-$ ute, followed by a final extension step at $72^{\circ} \mathrm{C}$ for $7 \mathrm{~min}$ utes. As for the pysrosequencing analysis, $10 \mu \mathrm{l}$ of bioti- nylated PCR product was immobilized to streptavidincoated Sepharose beads (Amersham Biosciences, Piscataway, NJ). After incubation, the beads were isolated and treated with $70 \%$ ethanol, denaturation buffer, and wash buffer. The beads then were released into designnated wells containing annealing buffer and 10 pmol of sequencing primer, followed by a 2 -minute incubation at $80^{\circ} \mathrm{C}$. Reproducibility was assessed by analyzing 42 samples in duplicate DNA.

Table 1. PCR and sequencing primers for CYP2C9*2, *3, *4, and *5.

\begin{tabular}{|c|c|c|c|}
\hline $\begin{array}{l}\text { CYP2C9 } \\
\text { Allele }\end{array}$ & Exon & Nucleotide change & Primers $^{1}$ \\
\hline \multirow[t]{5}{*}{ *2 } & 3 & $430 \mathrm{C}>\mathrm{T}$ & PCR Primers \\
\hline & & & F: 5'-GTATTTTGGCCTGAAACCCATA-3' \\
\hline & & & R: B-5'-CACCCTTGGTTTTTCTCAACTC-3' \\
\hline & & & Sequencing primer \\
\hline & & & 5'-GGGAAGAGGAGCATTGAGGC-3' \\
\hline$* 3$ & 7 & $1075 \mathrm{~A}>\mathrm{C}$ & PCR Primers for $* 3, * 4$, and $* 5$ \\
\hline$* 4$ & 7 & $1076 \mathrm{~T}>\mathrm{C}$ & F: B-5'-TGCACGAGGTCCAGAGAT-3' \\
\hline \multirow[t]{3}{*}{ *5 } & 7 & $1080 \mathrm{C}>\mathrm{G}$ & R: 5'-GATACTATGAATTTGGGACTTC-3' \\
\hline & & & Sequencing primer for $* 3, * 4$, and $* 5$ \\
\hline & & & 5'-GCTGGTGGGGAGAAG-3' \\
\hline
\end{tabular}

F, forward; R, reverse; B, biotin labeled. 


\subsection{Statistical Analysis}

Sample size was determined a priori by use of statistical power analysis with SAS software (SAS Institute, Cary, NC). Calculations revealed that a minimum of 120 samples is required for the genotype representation in the Lebanese population [11]. Statistical analyses were performed using the SigmaStat 3.5. The study samples alleles and genotype frequencies were estimated by gene counting method. The agreement with Hardy-Weinberg equilibrium of the observed genotypic distribution for the CYP2C9 gene was tested by chi-square tests. A P value of $<0.05$ was considered statistically significant. Population comparisons were also performed by Chi-square test of population differentiation.

\section{Results}

\subsection{Subjects Demographic Characteristics}

A total of 146 Lebanese subjects were included in the study, which aimed to determine the CYP2C $9 * 1,{ }^{*} 2, * 3, * 4$, and $* 5$ gene polymorphism prevalence in the Lebanese population. The study samples consisted of $51.9 \%$ and $48.1 \%$ males and females, respectively. The mean age was 20. 63 years (range: $18-69$ years) and the average BMI was $21.04 \mathrm{Kg} / \mathrm{m}^{2}$ (range: $17.15-27.48 \mathrm{Kg} / \mathrm{m}^{2}$ ).

\subsection{CYP2C $9 * 1, * 2, * 3, * 4$, and $* 5$ Gene Polymorphism Genotype Distribution in Lebanese and Hardy- Weinberg Equilibrium}

The detailed distribution of the CYP2C $9 * 2, * 3, * 4$, and $* 5$ genotypes in the Lebanese population is depicted in Table 2. The frequencies of the CYP2C $29 * 2$, CYP2C $9 * 3$, and $\mathrm{CYP} 2 \mathrm{C} 9 * 4$ alleles were $11.31 \%, 9.59 \%$, and $1.025 \%$ respectively. No CYP2C9*5 allele variants were found among the Lebanese study sample.

Volunteers could be divided into three CYP2C9 genotypes groups: subjects $(76.71 \%)$ with no variant alleles (CYP2C9*1*1; homozygous extensive metabolizers, EM), $21.23 \%$ with one variant allele (CYP2C $9 * 1 * 2, * 1 * 3$, $* 1 * 4$, and $* 1 * 5$; heterozygous intermediate metabolizers IM), and $2.06 \%$ with two mutated alleles (such as CYP2C9 $* 2 * 2, * 2 * 3, * 3 * 3, * 2 * 4$, and other homozygous variants/ poor metabolisers, $\mathrm{PM}$ ).

CYP2C9 allele and genotype frequencies did not deviate from Hardy-Weinberg equilibrium $(\mathrm{P}=0.743$, Fisher exact test).

Comparisons of population differentiation: CYP2C9 genotype frequencies in different populations as compared to those of Lebanese.

Table 2. Proportion of CYP2C9 amino acid variants, allele frequencies and phenotype in a Lebanese population of 146 subjects.

\begin{tabular}{|c|c|c|c|c|}
\hline CYP2C9 Polymorphism & Amino acid change & $\mathrm{n}$ & $\%$ & Phenotype \\
\hline \multirow[t]{3}{*}{$* 2(430 \mathrm{C}>\mathrm{T})$} & $\operatorname{Arg} / \operatorname{Arg}_{144}$ & 113 & 77.39 & \\
\hline & $\operatorname{Arg} / \mathrm{Cys}_{144}$ & 33 & 22.61 & \\
\hline & Cys/Cys 144 & 0 & 0 & \\
\hline \multirow[t]{3}{*}{$* 3(1075 \mathrm{~A}>\mathrm{C})$} & $\mathrm{Ile} / \mathrm{Ile}_{359}$ & 115 & 78.77 & \\
\hline & $\mathrm{Ile} / \mathrm{Leu}_{359}$ & 28 & 19.17 & \\
\hline & $\mathrm{Leu} / \mathrm{Leu}_{359}$ & 3 & 2.06 & \\
\hline \multirow[t]{3}{*}{$* 4(1076 \mathrm{~T}>\mathrm{C})$} & $\mathrm{Ile} / \mathrm{Ile}_{359}$ & 143 & 97.95 & \\
\hline & Ile/Thr 359 & 3 & 2.05 & \\
\hline & $\mathrm{Thr} / \mathrm{Thr}_{359}$ & 0 & 0 & \\
\hline \multirow[t]{3}{*}{ *5 $(1080 \mathrm{C}>\mathrm{G})$} & $\mathrm{Asp} / \mathrm{Asp}_{360}$ & 146 & 100 & \\
\hline & $\mathrm{Asp} / \mathrm{Glu}_{360}$ & 0 & 0 & \\
\hline & $\mathrm{Glu} / \mathrm{Glu}_{360}$ & 0 & 0 & \\
\hline \multirow[t]{3}{*}{$2 * 3 * 4 * 5$} & $* 1 * 1$ (wild) & 112 & 76.71 & Extensive \\
\hline & Heterozygous variants & 31 & 21.23 & Intermediate \\
\hline & Homozygous variants & 3 & 2.06 & Poor \\
\hline
\end{tabular}


The comparative analysis using genotype groups of different populations showed differences among Lebanese and other Caucasians (Table 3).

\section{Discussion}

CYP2C9 polymorphisms give rise to inter-individual and interethnic variability in the metabolism and disposition of several therapeutic agents. CYP2C9 polymorphisms may cause differences in the clinical response to these drugs. CYP2C9 various forms include CYP2C9*1 (wild type) and two well-characterized SNPs, an arginine-tocysteine change at codon 144 (Arg144Cys, CYP2C9*2), and isoleucine-to-leucine change at codon 359 (Ile359Leu, CYP2C9*3). CYP2C9*4 (an isoleucine-to- threonine change at codon 359 and CYP2C9*5 (an aspartic acid-toglutamic acid change at codon 360 ) as well as other polymorphisms have been also reported in different populations. Patients who have variant alleles of CYP2C9 require, for example, reduced maintenance doses of warfarin compared to those having wild type-alleles [12]. The *2/*2 homozygous variant leads to a reduction of approximately $12 \%$ of CYP2C9 activity and the $* 3 / * 3$ homozygous variant has $<5 \%$ of wild type CYP2C9 activity [13]. The $* 2$ and $* 3$ alleles, have been associated with an increased risk of warfarin over anticoagulation and bleeding events [14]. Alternate genotypes composed of 1 or more low-activity alleles also may account for the difficult-to control anticoagulation status in some patients [15]. The accumulated evidence suggests that the CYP2C9 genotype has been used to develop warfarindosing algorithms to avoid the morbidity associated with over anticoagulation [10].

Table 3. CYP 2C9 genotype frequencies in different populations as compared to those of Lebanese.

\begin{tabular}{|c|c|c|c|c|c|c|}
\hline \multicolumn{7}{|c|}{ CYP 2C9 allele frequencies in different populations } \\
\hline & Ref & & Genotype & & No of Subjects & Chi Square $P$ values \\
\hline & & $* w t / w t$ & $\mathrm{wt} / \mathrm{mut} *$ & mut/mut* & & \\
\hline Chinese & {$[16]$} & 98 & 2 & 0 & 265 & 0.001 \\
\hline Italians & {$[17]$} & 53 & 39 & 8 & 465 & 0.001 \\
\hline Japanese & {$[12]$} & 95 & 4 & 1 & 828 & 0.001 \\
\hline Sweden & {$[18]$} & 66 & 31 & 3 & 1496 & 0.003 \\
\hline Hungarian & [19] & 62 & 33.4 & 4.6 & 535 & 0.004 \\
\hline Turkish & {$[20]$} & 62 & 35 & 3 & 499 & 0.004 \\
\hline African Americans & {$[21]$} & 88 & 10 & 2 & 268 & 0.007 \\
\hline Iranian & {$[22]$} & 55 & 38 & 7 & 58 & 0.007 \\
\hline Bolivian & {$[23]$} & 84.6 & 15 & 0.4 & 778 & 0.01 \\
\hline British & {$[24]$} & 56 & 36 & 8 & 297 & 0.01 \\
\hline French & {$[25]$} & 63 & 30 & 6 & 126 & 0.03 \\
\hline Canadian & [26] & 59 & 38 & 3 & 51 & 0.04 \\
\hline Lebanese & Current study & 77 & 21 & 2 & 146 & 1 \\
\hline Omani & [27] & 80 & 19 & 1 & 189 & 0.6 \\
\hline Dutch & [28] & 70 & 28 & 2 & 60 & 0.546 \\
\hline European Americans & [21] & 70 & 27 & 3 & 292 & 0.3 \\
\hline Malays & [16] & 81 & 15 & 4 & 151 & 0.2 \\
\hline Russians & [29] & 68 & 29 & 3 & 298 & 0.172 \\
\hline Belgian & [30] & 67 & 29 & 4 & 121 & 0.157 \\
\hline Ethiopians & [31] & 87 & 12 & 1 & 150 & 0.085 \\
\hline Egyptians & [32] & 66 & 31 & 3 & 247 & 0.081 \\
\hline
\end{tabular}

*wt: wild type, mut: mutant. Statistical Significance $\mathrm{P} \leq 0.05$. 
Earlier studies have indicated differences in CYP2C9 enzyme activity may exist not only between the major races but also among different Caucasians populations. Consequently, further studies on different Caucasian ethnic groups are needed to provide relevant genotypic data for each population. To our knowledge, this is the first study that reports different CYP2C $9 * 2, * 3, * 4$, and $* 5$ genotypes in the Lebanese population (White Caucasians). Frequencies of CYP2C9 genotype polymorphisms resulted very high, showing a higher frequency of CYP $2 \mathrm{C} 9$ homozygous extensive metabolisers $(* 1 / * 1)$ compared to other Caucasians i.e., Southern Europe (Table 3). Additionally, CYP2C $9 * 5$ allele frequency was not found among the Lebanese study sample.

The ability to determine a patient's genotype helps future pharmacogenomic investigations and the transition of pharmacogenomics into mainstream clinical practice. This feature is necessary for situations in which randomization, or the start of drug therapy, is dependent on genotype determinations.

In conclusion, $\mathrm{CYP} 2 \mathrm{C} 9$ gene polymorphisms classified individuals mainly into extensive and intermediate metabolisers. This first report from Lebanon highlights a higher frequency of CYP2C9 extensive metabolisers compared to Europeans and North American Caucasians; a unique feature that serves a baseline clinical data for dosing of drugs metabolised by CYP 2C9 based on Lebanese patients' genotypes.

\section{Acknowledgements}

The study was supported by research grants of the Lebanese American University, Lebanon, and the Center for Pharmacogenomics at the University of Florida, Gainesville, USA.

\section{REFERENCES}

[1] C. R. Lee, J. A. Goldstein and J. A. Pieper, "Cytochrome P450 2C9 Polymorphisms: A Comprehensive Review of the in-vitro and Human Datam," Pharmacogenetics, Vol. 12, No. 3, 2002, pp. 251-263. doi:10.1097/00008571-200204000-00010

[2] D. Si, Y. Guo, Y. Zhang, L. Yang, H. Zhou and D. Zhong, "Identification of a Novel Variant CYP2C9 Allele in Chinese," Pharmacogenetics, Vol. 14, No. 7, 2004, pp. 465-469. doi:10.1097/01.fpc.0000114749.08559.e4

[3] K. Maekawa, N. Harakawa, E. Sugiyama, M. Tohkin, S. R. Kim, N. Kaniwa, et al., "Substrate-dependent Functional Alterations of Seven CYP2C9 Variants Found in Japanese Subjects," Drug Metabolism and Disposition, Vol. 37, No. 9, 2009, pp. 1895-903. doi:10.1124/dmd.109.027003

[4] G. P. Aithal, C. P. Day, P. J. Kesteven and A. K. Daly, "Association of Polymorphisms in the Cytochrome P450 CYP2C9 with Warfarin Dose Requirement and Risk of
Bleeding Complications," Lancet, Vol. 353, No. 9154, 1999, pp. 717-719. doi:10.1016/S0140-6736(98)04474-2

[5] U. I. Schwarz, "Clinical Relevance of Genetic Polymorphisms in the Human CYP2C9 Gene," European Journal of Clinical Investigation, Vol. 33, Suppl. 2, 2003, pp. 23-30. doi:10.1046/j.1365-2362.33.s2.6.x

[6] Y. R. Yoon, J. H. Shon, M. K. Kim, Y. C. Lim, H. R. Lee, J. Y. Park, et al., "Frequency of Cytochrome P450 2C9 Mutant Alleles in a Korean Population," British Journal of Clinical Pharmacology, Vol. 51, No. 3, 2001, pp. 277280.

[7] Y. B. Saab, W. Kabbara, C. Chbib and P. R. Gard, "Buccal Cell DNA Extraction: Yield, Purity, and Cost: A Comparison of Two Methods," Genetic Testing, Vol. 11, No. 4, 2007, pp. 413-416. doi:10.1089/gte.2007.0044

[8] T. Langaee and M. Ronaghi, "Genetic Variation Analyses by Pyrosequencing," Mutatiton Research, Vol. 573, No. 1-2, 2005, pp. 96-102.

doi:10.1016/j.mrfmmm.2004.07.023

[9] C. Aquilante, M. Lobmeyer, T. Langaee and J. Johnson, "Comparison of Cytochrome P450 2C9 Genotyping Methods and Implications for the Clinical Laboratory," Pharmacotherapy, Vol. 24, No. 6, 2004, pp. 720-726. doi:10.1592/phco.24.8.720.36074

[10] M. W. Hruska, R. F. Frye and T. Y. Langaee, "Pyrosequencing Method for Genotyping Cytochrome P450 CYP2C8 and CYP2C9 Enzymes," Clinical Chemistry, Vol. 50, No. 12, 2004, pp. 2392-2395. doi:10.1373/clinchem.2004.040071

[11] Y. B. Saab, P. R. Gard, M. S. Yeoman, B. G. Mfarrej, H. E. El-Moalem and M. J. Ingram, "Renin Angiotensin-System Gene Polymorphisms and Depression," Progress in Neuro-Psychopharmacology and Biology \& Psychiatry, Vol. 31, No. 5, 2007, pp. 1113-1118.

[12] J. D. Nunnelee, "Review of an Article: The International Warfarin Pharmacogenetics Consortium (2009). Estimation of the Warfarin Dose with Clinical and Pharmacogenetic Data. NEJM 360 (8): 753-64," Journal of Vascular Nursing, Vol. 27, No. 4, 2009, p. 109. doi:10.1016/j.jvn.2009.09.001

[13] A. R. Redman, "Implications of Cytochrome P450 2C9 Polymorphism on Warfarin Metabolism and Dosing," Pharmacotherapy, Vol. 21, No. 2, 2001, pp. 235-242. doi:10.1592/phco.21.2.235.34106

[14] M. K. Higashi, D. L. Veenstra, L. M. Kondo, A. K. Wittkowsky, S. L. Srinouanprachanh, F. M. Farin, et al., "Association between CYP2C9 Genetic Variants and Anticoagulation-Related Outcomes during Warfarin Therapy," Journal of the American Medical Association, Vol. 287, No. 13, 2002, pp. 1690-1698. doi:10.1001/jama.287.13.1690

[15] M. W. Linder, S. Looney and J. E. Adams, N. Johnson, D. Antonino-Green, N. Lacefield, et al., "Warfarin Dose Adjustments Based on CYP2C9 Genetic Polymorphisms," Journal of Thrombosis Thrombolysis, Vol. 14, No. 3, 2002, pp. 227-232. doi:10.1023/A:1025052827305

[16] C. H. Luo, A. Wang, R. H. Zhu, W. X. Zhang, W. Mo, B. N. Yu, G. L. Chen, D. S. Ou-Yang, X. H. Duan, A. M. 
Abd El-Aty and H. H. Zhou, "Gender Specific Association of CYP2C9*3 with Hyperlipidaemia in Chinese," British Journalof Clinical Pharmacology, Vol. 60, No. 6, 2005, pp. 629-631.

[17] S. Csilla, L. Lilla, S. Melinda, I. Takacs, T. Viola, P. Noemi, F. Andras and M. Bela, "Interethnic Differences of CYP2C9 Alleles in Healthy Hungarian and Roma Population Samples: Relationship to Worldwide Allelic Frequencies," Blood Cells, Molecules, and Diseases, Vol. 43, No. 3, 2009, pp. 239-242.

[18] M. Wadelius, L. Y. Chen, J. D. Lindh, N. Eriksson, M. J. Ghori, S. Bumpstead, et al., "The Largest Prospective Warfarin-Treated Cohort Supports Genetic Forecasting," Blood, Vol. 113, No. 4, 2009, pp. 784-790. doi:10.1182/blood-2008-04-149070

[19] S. Ozawa, B. Shoket, L. P. McDaniel, Y. M. Tang, C. B. Ambrosone, S. Kostic, et al., "Analyses of Bronchial Bulky DNA Adduct Levels and CYP2C9, GSTP1 and NQO1 Genotypes in a Hungarian Study Population with Pulmonary Diseases," Carcinogenesis, Vol. 20, No. 6, 1999, pp. 991-995. doi:10.1093/carcin/20.6.991

[20] O. Nihat, C. Nese, T. Burak, O. Songul, U. Huseyin, O. Dilaver, C. Mehmet and C. Figer, "The Impact of CYP2C9 and VKORC1 Genetic Polymorphism and Patient Characteristics upon Warfarin Dose Requirements in an Adult Turkish Population," Heart Vessels, Vol. 25, No. 2, 2010 , pp. 155-162.

[21] N. A. Limdi, G. McGwin, J. A. Goldstein, T. M. Beasley, D. K. Arnett, B. K. Adler, M. F. Baird and R. T. Acton, "Influence of CYP2C9 and VKORC1 1173C/T Genotype on the Risk of Hemorrhagic Complications in AfricanAmerican and European-American Patients on Warfarin," Clinical Pharmacology and Therapeutics, Vol. 83, No. 2, 2008, pp. 312-321. doi:10.1038/sj.clpt.6100290

[22] A. Lerena, P. Dorado, F. O'Kirwan, R. Jepson, J. Licinio and M. L. Wong, "Lower Frequency of CYP2C $9 * 2$ in Mexican-Americans Compared to Spaniards," Pharmacogenomics Journal, Vol. 4, No. 6, 2004, pp. 403-406. doi:10.1038/sj.tpj.6500278

[23] V. Heydy, K. Bravo-Villalta, K. N. Yamamoto, B. Ana and R. H. Yuko Okada, "Genetic Polymorphism of CYP2C9 and CYP2C19 in a Bolivian Population: An Investigative and Comparative Study," British Journal of Clinical Pharmacology, Vol. 61, No. 3, 2005, pp. 179-184.

[24] E. A. Sconce, T. I. Khan, H. A. Wynne, P. Avery, L. Monkhouse, B. P. King, et al., "The Impact of CYP2C9 and VKORC1 Genetic Polymorphism and Patient Characteristics upon Warfarin Dose Requirements: Proposal for a New Dosing Regimen," Blood, Vol. 106, No. 7, 2005, pp. 2329-2333. doi:10.1182/blood-2005-03-1108

[25] V. Siguret, I. Gouin, J. L. Golmard, S.Geoffroy, J. P. Andreux and E. Pautas, "Cytochrome P450 2C9 Polymorphisms (CYP2C9) and Warfarin Maintenance Dose in elderly Patients," La revue de médecine interne, Vol. 25, No. 4, 2004, pp. 271-274. doi:10.1016/j.revmed.2003.11.006

[26] M. Moridani, L. Fu, R. Selby, F. Yun, T. Sukovic, B. Wong, et al., "Frequency of CYP2C9 Polymorphisms Affecting Warfarin Metabolism in a Large Anticoagulant Clinic Cohort," Clinical Biochemistry, Vol. 39, No. 6, 2006, pp. 606-612. doi:10.1016/j.clinbiochem.2006.01.023

[27] M. Tanira, M. A. Al-Mukhaini, A. T. Al-Hinai, K. A. Al Balushi and I. S. Ahmed, "Frequency of CYP2C9 Genotypes among Omani Patients Receiving Warfarin and Its Correlation with Warfarin Dose," Community Genetics, Vol. 10, No. 1, 2007, pp. 32-37. doi:10.1159/000096279

[28] J. Van der Weide, L. S. Steijns, M. J. Van Weelden and K. de Haan, "The Effect Genetic Polymorphism of Cytochrome P450 CYP2C9 on Phenytoin Dose Requirement," Pharmacogenetics, Vol. 11, No. 4, 2001, pp. 287-291. doi:10.1097/00008571-200106000-00002

[29] S. N. Pschelina, A. E. Sirotkina, T. V. Taraskina, A. L. Vavilova, A. L. Shwarzman and E. I. Shwartz, "The Frequency of Cyochrome P450 2C9 Genetic Variants in the Russian Population and Their Associations with Individual Sensitivity to Warfarin Therapy," Thrombosis Research, Vol. 115, No. 3, 2005, pp. 199-203. doi:10.1016/j.thromres.2004.08.020

[30] A. C. Allabi, J. L. Gala, J. P. Desager, M. Heusterspreute and Y. Horsmans, "Genetic Polymorphisms of CYP2C9 and CYP2C19 in the Beninese and Belgian Populations," British Journal of Clinical Pharmacology, Vol. 56, No. 6, 2003, pp. 653-657. doi:10.1046/j.1365-2125.2003.01937.x

[31] S. A. Scott, L. Edelmann, R. Kornreich, M. Erazo and R. J. Desnick, "CYP2C9, CYP2C19 and CYP2D6 Allele Frequencies in the Ashkenazi Jewish Population," Pharmacogenomics, Vol. 8, No. 7, 2007, pp. 721-730. doi: $10.2217 / 14622416.8 .7 .721$

[32] H. Samar, H. Masahiro, N. Kaori, E. Mervat, M. Nadia, A. Mohammed and M. Michiano, "Allele and Genotype Frequencies of Polymorphic Cytochromes P 450 (CYP2C9, CYP2C19, CYP2EI) and Dihydropyrimidine Dehydrogenase (DPYD) in the Egyptian Population," British Journal of Clinical Pharmacology, Vol. 53, No. 6, 2002, pp. 596-603. 